\title{
El principio del control convencional. Desafíos en el marco del derecho internacional*
}

\author{
Dante Mauricio Negro Alvarado**
}

\begin{abstract}
RESUMEN
El presente trabajo aborda la figura del control convencional y examina cuáles son las posibilidades de aplicar este concepto dentro del marco que establece el derecho internacional general y dentro de los parámetros que determina el control de constitucionalidad. Se abordará la figura del control convencional difuso tal como ha sido postulado por la Corte Interamericana de Derechos Humanos, analizándola desde la perspectiva de la teoría de las fuentes del derecho internacional general, de la manera como los diferentes Estados de la región incorporan la norma internacional dentro de sus sistemas jurídicos internos y de la jerarquía que estos les asignan a dichas normas una vez incorporadas.
\end{abstract}

Palabras clave: derecho internacional, control convencional, control constitucional, sistema interamericano, derechos humanos, fuentes del derecho internacional, monismo, dualismo.

\section{The principle of conventional control. Challenges in the framework of international law}

\section{Abstract}

This paper addresses the figure of conventional control and examines the possibilities of applying this concept within the framework established by the general international law and within the parameters determined by the control of constitutionality. We will address the

\footnotetext{
* Las ideas vertidas por el autor en este trabajo son de su exclusiva responsabilidad y para nada comprometen a la Organización en la que trabaja.

** Abogado egresado de la Pontificia Universidad Católica del Perú donde además siguió estudios de post-grado en Derecho Internacional Económico. Máster en Derecho Internacional y Derechos Humanos por la Universidad de Notre Dame, Indiana. Director del Departamento de Derecho Internacional de la OEA y secretario técnico del Comité Jurídico Interamericano. Profesor en la Maestría en Protección Internacional de los Derechos Humanos de la Universidad de Alcalá, España. Correo electrónico: DNegro@oas.org

(iD) https://orcid.org/0000-0002-4655-9075
} 
figure of the diffuse conventional control as it has been used by the Inter-American Court of Human Rights, analizing it from the perspective of the theory of the sources of general international law; in the way in which different States of the region incorporate the international norm within their internal legal systems; and the hierarchy that they assign to said rules once they are incorporated.

Keywords: International law, control of conventionality, control of constitutionality, InterAmerican system, human rights, sources of international law, monism, and dualism.

\section{Introducción}

El presente trabajo aborda la figura del control convencional (conocido como «control de convencionalidad») desde una perspectiva del derecho internacional general. Partimos de la idea de que el control convencional no es exclusivo del sistema interamericano de derechos humanos aunque es en este sistema que ha encontrado su mayor desarrollo. En ese sentido, examinaremos cuáles son las posibilidades reales de aplicar este concepto dentro del marco que establece el derecho internacional general, poniendo de relieve la necesidad de evitar que se produzcan eventuales conflictos sustanciales entre dicho control convencional y el control de constitucionalidad que ejercen los jueces dentro de sus respectivas jurisdicciones internas.

En efecto, el derecho internacional de los derechos humanos se inserta dentro del marco del derecho internacional general, y se apoya en él para hacer uso de muchos conceptos e instituciones con miras a lograr su efectiva aplicación, como es el caso de: los principios generales del derecho como el pacta sunt servanda (que asegura el respeto de las obligaciones internacionales contraídas por el Estado); la definición de las condiciones para el surgimiento de la responsabilidad internacional y las formas de determinación de la reparación como su consecuencia inmediata; la posibilidad de la aplicación de la norma consuetudinaria a falta de una norma convencional; la conceptualización de lo que es una norma del Jus Cogens, entre otros innumerables ejemplos. Por ello, es sumamente importante no perder de vista en qué medida y con qué alcances el derecho internacional de los derechos humanos forma parte de este derecho internacional general, como una forma de garantizar el respeto de la seguridad jurídica en favor de todos los sujetos de la comunidad internacional.

De manera particular abordaremos la figura del control convencional difuso, postulado que ha tenido particular desarrollo en el sistema interamericano y que puede presentar los mayores desafíos en cuanto a su implementación. A través de un análisis de la teoría de las fuentes del derecho internacional general, de la manera como los diferentes Estados de la región incorporan la norma internacional dentro de sus sistemas jurídicos internos y de la jerarquía que estos le asignan a dichas normas 
una vez incorporadas, podremos establecer qué posibilidades reales existen para que el control convencional, tal como está postulado por la Corte Interamericana de Derechos Humanos, pueda ser implementado como una herramienta útil para la garantía y protección de los derechos humanos en la región. Debido al alcance específico de este trabajo, solo abordaremos estos tres temas que nos parecen filtros esenciales para establecer, al menos inicialmente, la conveniencia de utilizar esta figura.

El reto ante nosotros es pensar qué tipo de sistema de promoción y protección de los derechos humanos queremos dejar para las generaciones futuras, y empezar a trabajar para hacerlo realidad a través de propuestas que tengan la mejor posibilidad de insertarse y desarrollarse con éxito en el sistema jurídico en el cual operamos.

\section{El control convencional como mecanismo del derecho internacional general}

El control convencional es una herramienta del derecho internacional cuya aplicación se inicia en el momento en que un Estado se hace parte de un tratado, y tiene como objetivo brindar garantías al cumplimiento del mismo a través del establecimiento de un órgano jurisdiccional o un mecanismo ad hoc de seguimiento o supervisión. Este órgano jurisdiccional o mecanismo ad hoc tendrá la función de determinar si la conducta del Estado se adecúa o no a las obligaciones contenidas en el instrumento internacional de que se trate. Dicha determinación, así como la actuación del órgano o mecanismo, estarán reguladas por normas que en la mayoría de los casos son parte del tratado en cuestión o por el derecho internacional general.

El control convencional es pues un mecanismo propio del derecho internacional general, y se puede aplicar eventualmente a todo tratado internacional y no corresponde exclusivamente al sistema interamericano de los derechos humanos (en adelante «SIDH») en particular, o a los sistemas de derechos humanos en general, sino que es compartido por todos aquellos sistemas en los que se realiza la determinación antes descrita y que nosotros llamaremos determinación de adecuación. En ese sentido, los parámetros en los que se asienta dicho control convencional deberían estar determinados por el derecho internacional general, de manera tal de brindar la adecuada consistencia a la labor que realizan todos los tribunales que actúan en la esfera internacional y, sobre todo, a la manera como se implementan sus decisiones en las esferas internas de los Estados.

Como señala Sagües (s.f.,) dada su importancia, el control convencional (conocido también por un sector de la doctrina como «control de convencionalidad») se presenta como un instrumento eficaz con el que cuenta la Corte Interamericana de Derechos Humanos (en adelante «Corte $\mathrm{IADH}$ ») para asegurar el respeto, la garantía 
y el ejercicio efectivo de los derechos contenidos en la Convención Americana sobre Derechos Humanos (en adelante «CADH») y otros tratados interamericanos sobre derechos humanos ${ }^{1}$. Ferrer Mac-Gregor (2013), actual juez de la Corte IADH, afirma que el control convencional constituye la razón de ser de la Corte IADH. Siendo así, dicho control convencional debe plantearse de tal manera que cumpla con su objetivo fundamental. García Ramírez (2011), exjuez de la Corte IADH, señala que existe el riesgo de que esto no ocurra cuando se carece de un encaminamiento razonable, preciso y sistemático, y aparecen propuestas de control que no obedecen a un conocimiento profundo y a una conducción armoniosa de la interpretación jurisdiccional en esta materia. Nosotros agregaríamos que ese riesgo se profundiza cuando se pierde de vista el marco general en el cual dicho control convencional como institución jurídica debe insertarse, es decir, el derecho internacional general.

En ese sentido, debemos señalar que la Corte IADH, a través de las diversas sentencias que ha dictado en el transcurso de los años, ha ido desarrollando una definición que hoy en día incluye elementos que van más allá de la conceptualización que brinda el derecho internacional. Solo para poder contrastar inicialmente ambas definiciones, adelantaremos aquella que viene utilizando frecuentemente la Corte IADH, en el sentido de que el control convencional es la actividad que deben desarrollar todas las autoridades, órganos y poderes de un Estado parte de la $\mathrm{CADH}$ y de otros tratados interamericanos, consistente en aplicar ${ }^{2}$ el derecho internacional, específicamente la $\mathrm{CADH}$, otros tratados de derechos humanos ${ }^{3}$ y la jurisprudencia de la Corte $\mathrm{IADH}^{4}$, a efectos de armonizar, invalidar o inaplicar las disposiciones normativas y actos internos contrarios a los anteriores 5 . Debemos desde ya señalar que esta definición,

\footnotetext{
1 Esta labor existe en la práctica en el SIDH desde que la Corte IADH empezó a ejercer sus funciones de manera efectiva en 1986. Recordemos que si bien la Corte fue creada por la CADH, que a su vez fue adoptada el 22 de noviembre de 1969 y entró vigor desde el 18 de julio de 1978, dicho tribunal pudo establecerse solo en junio de 1979 cuando celebró su primera reunión en la sede de la Organización de los Estados Americanos (Washington, D.C.) y recibió su primer caso por parte de la Comisión Interamericana de Derechos Humanos en 1986 (caso Velásquez Rodríguez vs. Honduras, decidido en 1988), a partir de lo cual pudo empezar a ejercer el control convencional de manera efectiva.

2 La Corte IADH ha establecido que dicha aplicación debe ser hecha ex officio, entendiendo por esto que la obligación de las autoridades antes señaladas debe ejercerse sin la necesidad de que sea solicitado por las personas sujetas a la jurisdicción del Estado en cuestión. Esta característica viene desarrollada en el caso Trabajadores Cesados del Congreso vs. Perú. (Aguado Alfaro y otros) vs. Perú [Corte Interamericana de Derecho Humanos (Corte IADH, 2006)].

3 La Corte IADH también ha sostenido que puede interpretar disposiciones sobre derechos humanos que figuren en otros tratados internacionales, no únicamente americanos, a condición de que estos sean aplicables a algunos países de América (García Ramírez, 2011).

4 Por jurisprudencia de la Corte, esta ha entendido que incluye las opiniones consultivas, las sentencias (en el curso o al cabo de procedimientos contenciosos), las medidas provisionales, las resoluciones sobre cumplimiento y otras determinaciones que emite el tribunal interamericano en el ejercicio de sus atribuciones jurisdiccionales.

5 La Corte IADH afirmó en el caso Trabajadores Cesados del Congreso vs. Perú que el control convencional tampoco debe ejercerse sin considerar otros supuestos formales y materiales de admisibilidad y procedencia para ese
} 
tal como es planteada por la Corte IADH, no deriva del texto de la CADH sino de la evolución jurisprudencial misma de este tribunal (Ferrer Mac-Gregor, 2013), y se ha venido en denominar como "control convencional difuso".

Esta es una definición que amplía de manera sustancial el alcance del control convencional determinado por el derecho internacional general, y a lo largo de estas páginas analizaremos cuáles son las posibilidades reales de aplicarla sin que el derecho internacional general y el derecho interamericano de los derechos humanos entren en conflicto ya que, como incluso algunos defensores del principio del control convencional difuso admiten, este concepto implica otorgar efectos expansivos a la jurisprudencia de la Corte IADH, como si se tratase de un Tribunal Constitucional Latinoamericano lo cual, como es evidente, no es de fácil aceptación por parte de algunos países de la región (Ferrer Mac-Gregor, 2013).

García Ramírez (2016) señala acertadamente que es deseable llegar pronto a coincidencias básicas en torno a las cuestiones que suscita este tema las que a menudo, en sus propias palabras, han sido fomentadas por el entusiasmo y las crecientes expectativas. En su opinión, dichas coincidencias permitirán que el control convencional alcance la mejor implementación posible, que adquiera una uniformidad razonable en nuestra región, y que contribuya a la formación del ius commune, a la armonización y congruencia, a la definición plausible y admisible del orden jurídico y sus garantías (García Ramírez, 2016). El exjuez de la Corte IADH agrega que si esto no sucede, se corre el riesgo de alimentar la dispersión, que surjan contradicciones al interior de los países y decaiga la tutela continental de los derechos humanos ${ }^{6}$.

\footnotetext{
tipo de acciones. Así, la Corte IADH agrega que la actuación de dichas autoridades, órganos y poderes debe realizarse en el marco de las respectivas competencias de cada autoridad, órgano o poder y de las regulaciones procesales correspondientes, lo que significa que existe un límite a dicha capacidad de control convencional reconocida por el propio tribunal interamericano (Corte IADH, 2006). Con relación a la "competencia», la Corte IADH ha querido referirse a que corresponde a la ley la asignación de competencias de los órganos judiciales al amparo del principio de legalidad. Con relación a los «procedimientos», cuyo diseńo y alcance incumben igualmente a la ley, no se deriva que todos los jueces sean competentes para aplicar, sin mayores exigencias internas, el control convencional. Así, es perfectamente posible que el ordenamiento interno establezca competencias específicas (las cuales pueden recogerse en "grados» de competencia) para el despacho del control y la fuerza de las decisiones judiciales domésticas a este respecto. García Ramírez (2011) se refiere así al voto del juez Ferrer Mac-Gregor en el caso Cabrera García y Montiel Flores (2010) en el cual examina ciertos rangos de «intensidad» en las facultades de control reconocidas a los juzgadores que pudieran comprender, entre otros, la inaplicación de normas contrarias a la CADH, el planteamiento de una «duda de convencionalidad» ante órganos jurisdiccionales facultados para atenderla, o incluso la declaración de invalidez de la norma interna, según la competencia que la Constitución y las demás leyes nacionales le otorguen a cada juez. Es esto pues lo que determinará un grado mayor o menor en el control convencional. Ver el Caso Cabrera García y Montiel Flores vs. México (Corte IADH, 2010).

6 Años después, el propio García Ramírez haría alusión al concepto en términos bastante moderados. Según Castilla Juárez (2016), en una mesa de análisis que este compartió con aquel, García Ramírez afirmaba que no existe una respuesta suficiente, a escala continental y ni siquiera nacional acerca de lo que es el control convencional e invitaba a hacer uso de esta figura con razón y pertinencia, de lo contrario, el resultado podría no ser el deseado.
} 


\section{Las relaciones entre el control convencional y el control constitucional}

Una figura similar y que sirve para explicar los fundamentos del control convencional (y algunas de sus características) como herramienta para la «determinación de adecuación» es el «control constitucional». Como señala Vicente Gudiel y Véliz Arriaga (2016), históricamente, el surgimiento del constitucionalismo tuvo como fundamento el intento de imponer límites expresos a la actuación pública y sus eventuales excesos con el objetivo de proteger los derechos y libertades fundamentales del ciudadano. Así surgió el mecanismo del control constitucional que permitiría asegurar el respeto de la norma fundamental mediante la inaplicación o expulsión de todas aquellas normas jurídicas inferiores o subordinadas contrarias a sus disposiciones.

Con los terribles sucesos acontecidos durante las dos guerras mundiales, hubo necesidad de realizar nuevos planteamientos para asegurar la protección de los derechos humanos, más allá de las garantías contempladas hasta el momento por los regímenes constitucionales, es decir, más allá del plano estatal. Surge así el derecho internacional de los derechos humanos y la necesidad de establecer instancias internacionales cuyos mecanismos procesales fuesen capaces de supervisar, garantizar y asegurar, a través de un control convencional, el cumplimiento de aquellos estándares. Ambos mecanismos tienen pues como objetivo velar por el respeto y la eficacia de los derechos humanos reconocidos en el ámbito interno (control constitucional) y en el ámbito externo (control convencional), teniendo este último la característica de ser complementario al control de constitucionalidad que han de realizar los jueces nacionales (Vicente Gudiel et al., 2016).

Según García Ramírez (2011), la doctrina se referirá a dos grandes tipos de control constitucional, según las características que asuman en cada país. El «control de constitucionalidad difuso» asignará dicho control a un amplio número de jueces, incluso a todos los titulares de la función jurisdiccional llamados a pronunciarse sobre la constitucionalidad de las normas internas que en principio deben aplicar, y respecto de las cuales estarán autorizados para «desaplicar» cuando las consideren incompatibles con la ley fundamental a la que debieran ajustarse. Por su parte, el "control de constitucionalidad concentrado» será depositado en un órgano jurisdiccional supremo que no formará necesariamente parte del aparato judicial tradicional sino que desempeñará su función por encima de los órganos clásicos de la división de poderes, pudiendo declarar la invalidez de las normas con efecto general.

Como podemos ya inferir, estas formas de control, diseñadas para conducir la relación entre normas internas de diversa jerarquía pueden trasladarse al ámbito de la relación entre la norma internacional y la norma interna. Como afirma Rodas 
Balderrama (2016), aplicados estos conceptos al SIDH, los tribunales y cortes constitucionales ejercen el control constitucional de los actos del Estado, y la Corte IADH resuelve acerca de su convencionalidad. La Corte IADH recogerá ambos conceptos en un párrafo que establece muy bien las semejanzas y diferencias de ambas figuras, extraído del voto concurrente del exjuez García Ramírez en el caso Tibi vs. Ecuador de 2004:

En cierto sentido, la tarea de la Corte se asemeja a la que realizan los tribunales constitucionales. Estos examinan los actos impugnados — disposiciones de alcance general - a la luz de las normas, los principios y los valores de las leyes fundamentales. La Corte Interamericana, por su parte, analiza los actos que llegan a su conocimiento en relación con normas, principios y valores de los tratados en los que funda su competencia contenciosa. Dicho de otra manera, si los tribunales constitucionales controlan la «constitucionalidad», el tribunal internacional de derechos humanos resuelve acerca de la «convencionalidad» de esos actos. A través del control de constitucionalidad, los órganos internos procuran conformar la actividad del poder público - y, eventualmente, de otros agentes sociales - al orden que entraña el Estado de derecho en una sociedad democrática. El tribunal interamericano, por su parte, pretende conformar esa actividad al orden internacional acogido en la convención fundadora de la jurisdicción interamericana y aceptado por los Estados partes en ejercicio de su soberanía. (Corte IADH, 2004, párrafo 3)

No obstante, las semejanzas, cada mecanismo es aplicado a estructuras jurídicas distintas: así, el control de constitucionalidad es aplicado en el orden jurídico interno, y el control convencional en el orden internacional, cada uno a su vez con características diferentes. Tanto es así que el control constitucional y el control convencional podrían eventualmente entrar en conflicto (ya que el contenido y el alcance de las normas interna e internacional podrían ser distintos). Pero aún más importante es que el control difuso no se puede transpolar del orden interno al orden internacional de manera automática, principalmente porque el control de constitucionalidad difuso permite realizar dicho control a través de diversas instancias dentro de un marco jurídico único y con una jerarquía predeterminada. El control convencional difuso partiría de la misma premisa, es decir, que tanto el tribunal internacional como los tribunales internos pertenecen a una misma estructura jerárquica lo cual, como veremos en reiteradas oportunidades a lo largo de este trabajo, no es propio de la naturaleza del $\mathrm{SIDH}^{7}$.

Es por ello importante determinar los alcances de estas figuras. Esta determinación, en el caso del control convencional, debe ser hecha sobre la base del derecho inter-

\footnotetext{
7 Ver por ejemplo el párrafo 6 del voto razonado del ex juez García Ramírez en el caso Vargas Areco vs. Paraguay en que se señala que la afirmación de que la Corte IADH constituye una cuarta instancia no corresponde a la competencia de dicho tribunal ni a las características del juicio internacional sobre derechos humanos (Corte IADH, 2006).
} 
nacional general aunque teniendo en cuenta la naturaleza y particularidades propias del SIDH, con el objetivo de respetar y resguardar el andamiaje internacional que cuidadosamente se ha ido construyendo a través de los años y que brinda seguridad jurídica y la más efectiva aplicación de los derechos humanos. De allí la necesidad de establecer si el postulado del control convencional, particularmente el control convencional difuso, se puede aplicar análogamente al control difuso de constitucionalidad y si se adecúa o no plenamente a los principios establecidos por el derecho internacional general.

\section{El control convencional en el Sistema Interamericano de Derechos Humanos}

Si bien, como ya habíamos señalado, el control convencional existe en el SIDH desde que la Corte IADH empezó a ejercer sus funciones de manera efectiva, el término fue utilizado por primera vez por el exjuez García Ramírez en el año 2003 a propósito de su voto concurrente en el caso Myrna Marck Chang vs. Guatemala en los siguientes términos:

Para los efectos de la Convención Americana y del ejercicio de la jurisdicción contenciosa de la Corte Interamericana, el Estado viene a cuentas en forma integral, como un todo. En este orden, la responsabilidad es global, atañe al Estado en su conjunto y no puede quedar sujeta a la división de atribuciones que señale el Derecho interno. No es posible seccionar internacionalmente al Estado, obligar ante la Corte solo a uno o algunos de sus órganos, entregar a estos la representación del Estado en el juicio — sin que esa representación repercuta sobre el Estado en su conjunto- y sustraer a otros de este régimen convencional de responsabilidad, dejando sus actuaciones fuera del «control de convencionalidad» que trae consigo la jurisdicción de la Corte internacional. (cursivas nuestras) (Corte IADH, 2003, párrafo 27)

De este párrafo queremos destacar por ahora que bajo el término de control convencional tal como es utilizado por García Ramírez (o "control de convencionalidad», como él mismo lo llama), dicho control es el ejercido por la propia Corte IADH, y en el marco de su jurisdicción contenciosa. En efecto, cuando se refiere «al control de convencionalidad que trae consigo la jurisdicción de la Corte Internacional», no hace sino referirse a la atribución propia del tribunal interamericano.

El término fue utilizado nuevamente por García Ramírez en el 2006 a través de su voto razonado en el caso Vargas Areco vs. Paraguay en los siguientes términos:

La Corte Interamericana, que tiene a su cargo el «control de convencionalidad» fundado en la confrontación entre el hecho realizado y las normas de la Convención Americana, no puede, ni pretende — jamás lo ha hecho-, convertirse en una nueva y última instancia para conocer la controversia suscitada en el orden interno. La expresión de que el Tribunal interamericano constituye una tercera o cuarta instancia, y en todo 
caso una última instancia, obedece a una percepción popular, cuyos motivos son comprensibles, pero no corresponde a la competencia del Tribunal, a la relación jurídica controvertida en este, a los sujetos del proceso respectivo y a las características del juicio internacional sobre derechos humanos. (cursivas nuestras) (Corte IADH, 2006, párrafo 6)

García Ramírez resalta aquí dos conceptos fundamentales. El primero tiene que ver con el hecho de que es la Corte IADH la que tiene a su cargo el control convencional. El segundo está en relación con el contenido mismo del control que queda definido como la confrontación entre el hecho realizado y las normas de la CADH. Ambos elementos guardan consonancia con la definición que propone el derecho internacional general analizado anteriormente.

Ese mismo año, en 2006, se daría inicio al desarrollo jurisprudencial de lo que se conocería después como el «control convencional difuso» a partir del caso Almonacid Arellano vs. Chile, como un desarrollo y ampliación del concepto del «control convencional concentrado».

En este caso la Corte IADH realiza una formulación que tiene como resultado trasladar el deber del ejercicio del control convencional a cargo del tribunal interamericano a los jueces del poder judicial de los Estados parte en la CADH. Dicho deber tendría además que cumplirse no solo con base en las disposiciones de la CADH sino también con base en la interpretación que de la misma convención ha de hacer el propio tribunal interamericano. En dicha sentencia, la Corte estableció lo siguiente:

La Corte es consciente que los jueces y tribunales internos están sujetos al imperio de la ley y, por ello, están obligados a aplicar las disposiciones vigentes en el ordenamiento jurídico. Pero cuando un Estado ha ratificado un tratado internacional como la Convención Americana, sus jueces, como parte del aparato del Estado, también están sometidos a ella, lo que les obliga a velar porque los efectos de las disposiciones de la Convención no se vean mermadas por la aplicación de leyes contrarias a su objeto y fin, y que desde un inicio carecen de efectos jurídicos. En otras palabras, el Poder Judicial debe ejercer una especie de "control de convencionalidad» entre las normas juridicas internas que aplican en los casos concretos y la Convención Americana sobre Derechos Humanos. En esta tarea, el Poder Judicial debe tener en cuenta no solamente el tratado, sino también la interpretación que del mismo ha hecho la Corte Interamericana, intérprete última de la Convención Americana. (cursivas nuestras) (Corte IADH, 2006, párrafo 124)

Así pues, la Corte IADH va más allá del concepto tradicional del control convencional y formula una definición con alcances propios y consecuencias específicas para el ordenamiento jurídico interamericano, el cual se irá ampliando aún más con el transcurso de los años. En ese sentido, el sistema interamericano de derechos humanos empezará a manejar un concepto de control convencional con alcances totalmente nuevos. Así, los dos elementos novedosos y que diferencian a esta 
modalidad del control convencional concentrado serán, por un lado, que el control ha de hacerse por jueces nacionales y, por el otro, que incluye las interpretaciones de la Corte IADH y no solo las normas das en los tratados internacionales o que surgen de otras fuentes principales del derecho internacional.

Surgen aquí algunas interrogantes fundamentales. Por ejemplo, debemos preguntarnos sobre los estándares que han de servir de referencia para ejercer el control convencional, independientemente de quién lo ejerza, a saber, si estos son solo los contenidos en las normas convencionales o si existe un fundamento válido, en el marco de la teoría de las fuentes del derecho internacional para incluir también los estándares contenidos en la jurisprudencia. Además, debemos necesariamente abordar la temática de las formas en que se incorpora la norma internacional a los ordenamientos jurídicos internos, sobre todo con relación a aquellos países que adoptan el sistema dualista, en los cuales una norma internacional se hace obligatoria internamente una vez culminado el proceso de incorporación respectivo, requisito previo sin el cual no tendría por qué ser conocida y mucho menos aplicada por los operadores domésticos. Por otro lado, una vez incorporada la norma internacional, debemos preguntarnos cuál es la jerarquía que ella adquiere dentro de la estructura jurídica interna del Estado en cuestión vis a vis las demás normas internas. En el caso de que una norma internacional en materia de derechos humanos tenga una jerarquía inferior a la Constitución y exista una contradicción en el alcance y contenido de ambas, necesariamente debería primar la norma constitucional, independientemente del eventual y posterior surgimiento de la responsabilidad internacional para dicho Estado, principio por lo demás ampliamente aceptado en el derecho internacional general, pero que opera solo cuando se han agotado todos los recursos disponibles de la justicia interna de un Estado, y no antes.

El tema de las fuentes del derecho internacional tiene relevancia tanto cuando se aplica la figura del control convencional concentrado como la del control convencional difuso. Los dos últimos temas sin embargo, el de la incorporación y el de la jerarquía, presentan una importancia particular para esta última. En efecto, cuando estamos ante el control convencional concentrado, tanto el tema de la forma en que se incorpora la norma internacional como la jerarquía que tendrá posteriormente dentro del ordenamiento interno, son irrelevantes para el juez internacional que, en todo caso, se guiará por el principio de la primacía del derecho internacional al momento de determinar el surgimiento de la responsabilidad internacional, en aplicación del artículo 27 de la Convención de Viena sobre el Derecho de los Tratados de 1969 la que, recogiendo la costumbre internacional, establece que una parte no podrá invocar las disposiciones de su derecho interno como justificación del incumplimiento de un tratado. Contrariamente, para el juez interno es distinto. En la medida en que dicho 
juez está sujeto a su normativa interna, el hecho de que una norma internacional se considere incorporada o no, así como la jerarquía que tengan las distintas normas de su sistema jurídico (incluida las normas internacionales ya incorporadas), tendrá un peso importante para la determinación de su decisión final en un caso concreto. El hecho de que su conducta conduzca eventualmente al surgimiento de la responsabilidad internacional del Estado y del cual es agente constituye en todo caso un elemento de consideración adicional pero no determinante al momento de adoptar dicha decisión, en tanto y en cuanto su deber principal será actuar de acuerdo con la normativa que está en vigor en su propio ordenamiento jurídico.

En los próximos acápites abordaremos cada uno de estos problemas.

Aunque ajeno a la temática del derecho internacional, tampoco podemos dejar de llamar la atención sobre la amplitud del concepto que la Corte IADH maneja con relación a los operadores que están llamados a hacer uso del control convencional difuso. En efecto, si bien el postulado surgió inicialmente con relación a una actividad que debía ejercer el Poder Judicial, luego se consideró como una función y tarea de cualquier autoridad pública. Así, luego de la referencia hecha a este tema en el caso Almonacid Arellano vs. Chile, en el caso Gelman vs. Uruguay de 2011, la Corte IADH indicó que el ejercicio del control convencional le corresponde a todo el aparato gubernamental, es decir, a todas las autoridades públicas y todos sus órganos, incluidas las instancias democráticas, jueces y demás órganos vinculados a la administración de justicia en todos sus niveles (Vicente Gudiel et al., 2016). Como señala García Ramírez (2011), con el tiempo, la figura del control convencional difuso se extenderá a funcionarios públicos con diversas atribuciones primarias y preparación profesional, extendiéndose a servidores públicos de todos los rangos, especialidades y competencias: desde miembros de la fuerza pública hasta docentes y funcionarios de salud, desde empleados del servicio postal hasta operarios de la fuerza pública y órganos de la administración pública central y descentralizada, y así sucesivamente. Esta amplitud conceptual trae consigo serios problemas de aplicación práctica.

Para efectos de simplificar el alcance de este trabajo, en adelante nos referiremos constantemente a los jueces y operadores internos como un todo, aunque entendiendo que las conclusiones a las que arribemos se aplicarán también al amplio universo de funcionarios que intenta contemplar la Corte IADH.

Antes de terminar este punto queremos referirnos a un elemento adicional y que a nuestro juicio aporta la mayor novedad en el razonamiento de la Corte IADH a este respecto. El concepto tradicional de control convencional pone el énfasis en la conducta del Estado, es decir, en la determinación de si esta se adecua o no a las obligaciones contenidas en el instrumento internacional, mientras que la nueva conceptualización 
que esgrime la Corte IADH pone énfasis en la confrontación de las normas nacionales con las disposiciones de la $\mathrm{CADH}$ y de otros instrumentos internacionales.

Si bien la adopción de las normas nacionales para implementar las normas internacionales es el resultado objetivo de la conducta estatal, no debemos olvidar que la existencia o no de las mismas y su contenido son solo un elemento más a considerar en la determinación de la responsabilidad internacional del Estado. En efecto, podría suceder que, no obstante la ausencia de ley o que una ley interna contradiga el estándar internacional, el Estado decida reparar a la víctima particular en su derecho, en cuyo caso el asunto no se elevaría para la consideración del tribunal internacional para ejercer el control convencional y determinar la responsabilidad internacional. Podría además suceder que el Estado en cuestión decida posteriormente a la producción del hecho y la reparación del caso avanzar hacia un cambio legislativo, el cual pudo no haber logrado antes debido a la premura del tiempo o a la complejidad de su sistema interno para adoptar leyes específicas (esto sucede mucho en los casos en que los Estados son federados y las competencias legislativas son muy dispersas). Así pues, el pasar de contrastar la conducta del Estado con el estándar internacional a contrastar el contenido de la legislación interna con dicho estándar, no solo desconoce la naturaleza misma del régimen de determinación de responsabilidad internacional y los casos en que dicho proceso debe iniciarse, sino que no toma en cuenta la naturaleza misma del derecho internacional de los derechos humanos que deja en manos del Estado la posibilidad ser él el primero en subsanar una violación de un derecho humano específico en su esfera interna de actuación.

\section{El uso de las fuentes del derecho internacional en el control convencional difuso}

Ya habíamos señalado anteriormente que en el caso Almonacid Arellano vs. Chile, de 2006, la Corte IADH estableció que en la tarea de ejercer el control convencional, los jueces internos deben tener en cuenta también la interpretación que ha hecho dicho tribunal con relación a la $\mathrm{CADH}$.

Esta afirmación plantea en primer lugar la pregunta de si la Corte IADH es una cuarta instancia dentro del sistema interamericano de los derechos humanos. Pues solo en ese supuesto, y aceptando que forma parte de la estructura jerárquica de los tribunales internos de los países en la región es que podríamos sostener eventualmente el carácter vinculante de sus interpretaciones con relación a los tribunales que estarían subordinados a ella.

Sobre el particular, el propio ex juez Sergio García Ramírez ha emitido una opinión suficientemente clara. En el párrafo 6 de su voto razonado en el caso Vargas Areco 
vs. Paraguay, mencionado párrafos atrás, se señala que «[...] la Corte Interamericana no puede ni pretende $[\ldots]$ convertirse en una nueva y última instancia para conocer la controversia suscitada en el orden interno [...] No corresponde a la competencia del Tribunal, a la relación jurídica controvertida en este, a los sujetos del proceso respectivo y a las características del juicio internacional sobre derechos humanos» (Corte IADH, 2006, p. 1).

Si bien algunos autores sostienen que «la jurisdicción interna no puede desvincularse de la interpretación hecha por la justicia supraestatal» (Gozaíni, 1998, pp. 819 y 828), refiriéndose con ello a la Corte $\mathrm{IADH}$, estos malinterpretan la estructura jurídica del sistema interamericano en el cual no existe un tribunal o justicia con el carácter de «supraestatal».

En efecto, tal como sostiene Vio Grossi (2015a), actual juez de la Corte IADH,

[...] el tema de los derechos humanos no ha dado lugar a una transferencia de competencias de instancias nacionales a una instancia internacional». El juez abunda al seńalar que «no existe en la actualidad y no obstante que parte de la doctrina lo proclame como una realidad, una experiencia supranacional en este campo del Derecho. Lo imaginado $[\ldots]$ ha devenido más bien en una utopía y, por lo mismo, por el momento irreal o inalcanzable. (p. 1)

Debemos recordar que el propio preámbulo de la $\mathrm{CADH}$, que por lo demás es el instrumento jurídico que crea la Corte IADH, determina en su párrafo 2 la «naturaleza convencional coadyuvante o complementaria» de la protección internacional con relación a aquella que ofrece el derecho interno de los Estados americanos. En efecto, la Corte IADH no es un tribunal supranacional dentro del SIDH, y por ende tampoco constituye una cuarta instancia que podría eventualmente llevarnos a considerar sus fallos e interpretaciones como decisiones vinculantes para los tribunales internos. Como bien afirma Vio Grossi (2015b, p. 100), «la Corte no debe ni puede ser percibida como una cuarta instancia, pues si lo fuese, debería fallar conforme, además de la Convención, al derecho nacional del correspondiente Estado, lo que no le es permitido".

Además, considerar a la Corte IADH como una cuarta instancia significaría desconocer la existencia de una instancia intermedia que opera entre dicho tribunal y los tribunales internos de los países. Nos referimos a la Comisión Interamericana de Derechos Humanos la que actúa como un filtro entre ambos y retiene para sí de manera exclusiva la decisión sobre qué casos pueden ser enviados para conocimiento de la Corte y cuáles no. Es decir, sin esta decisión previa de la Comisión, la Corte no tomaría conocimiento de un caso particular, característica totalmente ajena a la propia noción de ser un tribunal de alzada o una cuarta instancia. 
Una segunda consideración por abordar es si la jurisprudencia de los tribunales internacionales, independientemente de ser o no supranacionales o constituir una cuarta instancia, puede llegar a ser vinculante, no ya para los jueces internos sino para los Estados en general, es decir, si dichos tribunales internacionales tienen capacidad para crear derecho o ser fuente creadora de normas jurídicas. Sobre este punto también ha habido cierta confusión en el empleo de los términos y la conceptualización no ha sido lo suficientemente clara.

La jurisprudencia de los tribunales internacionales tiene como objetivo general indicar la existencia, el contenido y el sentido de las normas de derecho, así como determinar el derecho aplicable a cada caso. Ahora bien, tal como sucede en el caso de la Corte Internacional de Justicia, que es el tribunal internacional por excelencia, las decisiones de estos tribunales no son obligatorias sino para las partes en litigio y respecto del caso que ha sido decidido. Así lo establece el artículo 59 del Estatuto de 1945 de dicho tribunal.

Este postulado aplicable a la Corte Internacional de Justicia se extiende a las decisiones de todos los demás tribunales internacionales. Como lo establece Becerra (1998, p. 433) refiriéndose a la Corte IADH, «las decisiones de la Corte tienen las características de relatividad: son válidas para las partes y el caso concreto que resuelven». Así lo establece expresamente el artículo 68,1 de la CADH que señala que los Estados parte en la Convención se comprometen a cumplir la decisión de la Corte en todo caso en que sean partes, limitando pues de esta manera el alcance de las decisiones de la Corte en el sentido antes expresado.

Este postulado se fundamenta además en la teoría general de las fuentes del derecho internacional, según la cual, las fuentes primarias del derecho internacional son los tratados, la costumbre y los principios generales del derecho, mientras que las decisiones judiciales y las doctrinas de los publicistas de mayor competencia de las distintas naciones son un medio auxiliar para la determinación de las reglas de derecho, es decir, de aquellas reglas que emanan de las fuentes primarias. Así lo establece el artículo 38 del propio Estatuto de la Corte internacional de Justicia.

En ese sentido, las decisiones judiciales (y bajo este concepto nos referimos a las decisiones tanto de los tribunales internacionales como de los internos - es decir, el Estatuto de la Corte Internacional de Justicia pone al mismo nivel las sentencias emanadas de ambos tipos de tribunales), no son fuente autónoma o creadora de derecho sino que cumplen una función probatoria de la existencia de las normas jurídicas e interpretativa del contenido de las mismas, obviamente en aquellos casos en que cabe dicha interpretación. 
Debemos reconocer que la función probatoria e interpretativa de la jurisprudencia internacional ha tenido la gran virtud de aplicar reglas jurídicas deduciéndolas de los principios generales del derecho y de las prácticas estatales convencionales o consuetudinarias, explicándolas y profundizándolas, y otorgándoles una certeza de la que a veces pueden carecer (especialmente cuando se trata del derecho consuetudinario), permitiendo de este modo lograr verdaderos y significativos avances en el desarrollo del derecho internacional. Incluso, la jurisprudencia ha contribuido a la formación y transformación de ese derecho. Sobre la base de todo ello, el valor de las decisiones de la Corte IADH debe ser tenido en la más alta de las consideraciones. Pero derivar de esta afirmación que las decisiones judiciales de cualquiera de estos tribunales pueden ser generadoras per se de derecho va en contra de los postulados ampliamente aceptados en el derecho internacional general y de la teoría de las fuentes en particular.

Como señala el juez Vio Grossi, la jurisprudencia

[...] es una fuente que solo seńala el sentido y alcance de los que ha creado una de las fuentes autónomas, es decir, un tratado, una norma consuetudinaria, un principio general del derecho o eventualmente, un acto jurídico unilateral. La jurisprudencia internacional, entonces, no es suficiente para sustentar por sí sola y de manera exclusiva lo resuelto por un tribunal internacional, incluido el interamericano de derechos humanos (Vio Grossi, 2015a, p. 2).

Adicionalmente, la propia jurisprudencia interamericana necesariamente se debe sustentar en lo que establece la CADH. Por tanto, es esta la fuente primaria del derecho aplicable cuando se le otorga a la Corte IADH, en el artículo 62.3, la función de conocer de cualquier caso relativo a la interpretación y aplicación de las disposiciones de la misma que le sea sometido (Vio Grossi, 2015b). En buena cuenta pues, son principalmente los tratados como fuente de derecho internacional, los generadores últimos de las normas jurídicas, tanto primarias (creadoras de obligaciones específicas) como aquellas encargadas de establecer los alcances y limitaciones de las competencias de los tribunales internacionales que las aplicarán. Incluso si dicha jurisprudencia se emitiera en el marco de una sociedad de subordinación o integración (en cuyo caso si estaríamos ante la presencia de un tribunal con características supranacionales, que como vimos anteriormente no es el caso en el sistema interamericano), su obligatoriedad brotaría de las competencias delegadas o transferidas por parte de los Estados en sustitución de las pertinentes competencias estatales (Vio Grossi, 2015b). Dicha obligatoriedad no surgiría de la naturaleza misma de la sentencia en cuestión.

No podemos ignorar sin embargo que ciertos sectores sostienen que las decisiones de la Corte IADH en asuntos contenciosos son inmediatamente obligatorias, vinculantes, de forzosa observancia y cumplimiento para todos los Estados que aceptaron la compe- 
tencia contenciosa de dicho tribunal. García Ramírez (2011) señala que varios altos tribunales como en el caso de la Sala Constitucional de la Suprema Corte de Costa Rica, el Tribunal Constitucional de Bolivia, la Suprema Corte de Justicia de República Dominicana, el Tribunal Constitucional de Perú, la Corte Suprema de Justicia de la Nación de Argentina y la Corte Constitucional de Colombia han reconocido a la jurisprudencia de la Corte IADH eficacia vinculante o fuerza orientadora, independientemente de que aquella corresponda a casos que atañen directamente a los Estados respecto de los cuales actúan esos tribunales o a terceros Estados sujetos a la $\mathrm{CADH}$.

Debemos sin embargo preguntarnos si en estos casos, la obligatoriedad de la aplicación del precedente internacional en el marco del uso del control convencional difuso proviene de la propia naturaleza de la jurisprudencia de la Corte IADH o de la propia iniciativa soberana de las autoridades internas de utilizar dicho criterio interpretativo. No debemos pues perder de vista cual es la fuente original de esta fuerza vinculante que no podría ser ni la jurisprudencia en sí misma ni el propio principio del control convencional esgrimido por la Corte IADH.

Creemos pues que la jurisprudencia tiene una relevancia jurídica especial y no solo para los Estados que han reconocido la competencia de la Corte IADH o que son parte en la CADH sino para todos los Estados miembros de la OEA, pues en buena cuenta los estándares internacionales en materia de derechos humanos no solo provienen de las convenciones internacionales sino de otras fuentes de derecho internacional, incluso de las propias resoluciones de la Asamblea General de dicha Organización (en forma de soft law). Pero dicha relevancia jurídica es la misma que podría tener la doctrina en tanto fuente auxiliar del derecho internacional o el propio soft law antes referido, lo cual no las convierte per se en fuentes generadoras de normas internacionales con carácter vinculante.

¿Cuál sería entonces la función que cumple la jurisprudencia de la Corte IADH si no es la de servir de precedente «obligatorio», lo que para cierto sector de la doctrina es una pre condición para la eficacia plena del principio del control convencional difuso?

La función es doble. En primer lugar y como lo habíamos ya expresado, las sentencias son obligatorias para las partes en el caso específico, y por lo tanto un Estado parte en la $\mathrm{CADH}$ que ha reconocido como obligatoria la competencia de la Corte sobre un caso relativo a la interpretación o aplicación de la Convención al amparo del artículo 62 de dicho instrumento, y que es llevado ante su jurisdicción, debe acatar lo que establece dicho tribunal.

Una segunda función, y quizás tan importante como la primera, es la que señala Vio Grossi (2015a) en el sentido de que la jurisprudencia también tiene un carácter preventivo, es decir, los Estados que no han sido parte en un caso específico son 
advertidos, mediante dicha jurisprudencia, que si proceden en forma distinta a lo dispuesto en ella, corren el riesgo de incurrir en responsabilidad internacional.

Debemos señalar por último que la «interpretación» como herramienta jurídica de un tribunal internacional, como el caso de la Corte IADH, tiene como objetivo determinar el sentido y el alcance de la norma. No tiene como función la creación de nuevas normas jurídicas, lo que por otro lado estaría en contraposición con la naturaleza misma de las decisiones judiciales internacionales examinada anteriormente. Ahora bien, esta determinación no se hace en abstracto, sino en relación con un caso particular y concreto al cual la norma preexistente debe aplicarse. Esto significa que las características propias del caso en cuestión determinarán en buena medida el alcance mismo de la interpretación de la norma. En buena cuenta, las circunstancias específicas del caso son las que llenarán de contenido y justificarán por lo demás el ejercicio mismo de interpretación. El resultado de dicho procedimiento tendrá así un alto componente objetivo relacionado con el asunto que se está ventilando. En consecuencia, dicha interpretación no podría ser extensiva a otros casos que no repliquen exactamente las mismas circunstancias que el asunto precedente, lo cual es raro encontrar. Más allá de estos alcances, se estaría eventualmente creando de forma indirecta, una nueva norma jurídica la cual no tendría vocación de aplicación general, vocación que está en la naturaleza misma de la norma internacional.

Así pues, por todas estas razones, tanto por la definición propia de la «interpretación» como herramienta en el ámbito jurídico, como por la teoría de las fuentes del derecho internacional que otorga a las decisiones de los tribunales internacionales el carácter de fuente auxiliar del derecho, no se puede sostener que la jurisprudencia de la Corte IADH deba ser considerada un precedente obligatorio para la actuación de los jueces internos de los Estados, salvo que ellos mismos decidan aceptarlo de esta manera. Todo ello además de una consideración adicional, que por ser última no es menos importante, y es que la mayoría de los países que han reconocido la competencia de la Corte IADH provienen de una tradición romano-germánica (derecho civil) en la que la principal fuente de derecho es la ley, y en la cual los precedentes jurisprudenciales no tienen el peso que pueden revestir en el common law, sistema legal basado primordialmente en las decisiones adoptadas por los tribunales (derecho consuetudinario). La casi totalidad de Estados que actualmente reconocen la competencia contenciosa de la Corte IADH provienen de una tradición jurídica preeminentemente civilista y no del common law.

Con base en todo lo anterior, podemos afirmar que los alcances que la Corte IADH desea darle al control convencional difuso encuentra serias limitantes tanto en el derecho interno de los Estados como en el derecho internacional general. En primer lugar porque las decisiones judiciales no son fuente principal del derecho interna- 
cional, es decir, no generan normas vinculantes para los Estados y por ende su contenido solo es obligatorio para las partes en litigio y respecto del caso que ha sido decidido. En segundo lugar, porque sus interpretaciones no pueden considerarse como un criterio obligatorio para los tribunales internos de los Estados en tanto la Corte IADH no es un tribunal supranacional ni constituye una cuarta instancia con relación a un caso específico. Podemos sostener en cambio que las decisiones de la Corte IADH, incluyendo el alcance de sus interpretaciones allí incluidas, si son un medio idóneo para indicar la existencia y el contenido de las normas de derecho internacional cuando por ejemplo las mismas provienen del derecho consuetudinario o se derivan de principios generales del derecho, así como para determinar el sentido de las normas convencionales existentes cuando dicho sentido no sea lo suficientemente claro o esté sujeto a discrepancias. La ventaja de esta doble contribución de la actuación de la Corte IADH es que permitirá a los Estados contar con más elementos de juicio con relación a la eventual determinación de su responsabilidad internacional y con mayores posibilidades y oportunidades de revertir una situación en el fuero interno antes de que un caso se eleve al plano internacional. Sin embargo, derivar de ello una obligación puntual con relación a los jueces internos de ejercer un control convencional a ese nivel implicaría desconocer la manera como está estructurado actualmente el derecho internacional general y el sistema interamericano de los derechos humanos en particular. Todo ello sin mencionar el hecho de que el propio postulado del control convencional difuso tiene su origen en la propia jurisprudencia de la Corte IADH, y por lo tanto, surge de una fuente auxiliar del derecho internacional que en sí misma no podría ser generadora de normas vinculantes.

\section{El monismo y el dualismo como complemento y desafío para el control convencional}

Un tema de la mayor relevancia y con implicancias sobre la aplicación del control convencional tiene que ver con la relación que existe entre el derecho internacional y los derechos internos de los países. Como bien afirma Pastor Ridruejo, 1986, p. 159):

[...] la importancia de las relaciones entre el derecho internacional y los derechos internos radica en el hecho de que la eficacia real del primero depende en muy amplia medida de la fidelidad con que los derechos nacionales se conformen a las normas internacionales y les den efecto. Es esencial en este sentido que el derecho nacional facilite el cumplimiento del derecho internacional y más aún que, en caso de conflicto, el derecho del Estado no sea obstáculo para la observancia de las normas internacionales.

Esta afirmación es de la mayor relevancia para el derecho internacional de los derechos humanos y su efectiva implementación en los derechos internos de los Estados, 
y coincide con el objetivo que se persigue con el control convencional, sobre todo con el control convencional difuso, a saber, el logro de la mayor adecuación posible.

Ahora bien, los alcances y la manera como se define la relación entre el derecho internacional y el derecho interno son establecidos por diversos países de diferentes maneras, y según el método que estos adopten nos encontraremos frente a una doctrina específica, ya sea la doctrina dualista, la doctrina monista o frente a alguna doctrina ecléctica o conciliadora, las cuales pasaremos a desarrollar. En este punto no nos referiremos al caso particular de la incorporación de la costumbre internacional o de los principios generales del derecho a los ordenamientos internos, dado que la particular complejidad de este tema rebasa los alcances de este trabajo. Creemos que por ahora la referencia específica a los tratados internacionales basta para dejar claras las bases de nuestra propuesta.

La doctrina dualista postula que el ordenamiento jurídico internacional (incluido el derecho internacional de los derechos humanos) y los ordenamientos jurídicos internos son dos sistemas distintos en atención a diversos criterios, tanto por lo que se refiere a los procesos de formación y aplicación de sus normas, como por su distinto ámbito de regulación material. No basta así con la manifestación de la voluntad para obligarse por un tratado para que este genere efectos al interior de un Estado, sino que es necesario un proceso adicional y posterior de incorporación o recepción de la norma internacional al derecho interno de los países a través de un acto expreso. Como afirma Jiménez Piernas (2011), las normas internacionales no son directamente aplicables por los órganos internos, sino que, para serlo, deben ser transformadas en normas internas, mediante un acto expreso del legislador nacional.

A nuestro juicio, el principal objetivo de este acto de recepción es que la norma internacional sea conocida efectivamente por los operadores internos y ser así aplicada por ellos y, sobre todo, que los particulares conozcan también con certeza las normas a las que estarán eventualmente sometidos o los derechos de los que son titulares.

Vargas Carreño sintetiza muy bien las implicancias de adoptar la doctrina dualista para los diversos órganos dentro de la estructura estatal:

De esa manera, las obligaciones impuestas por una norma de derecho internacional a los particulares o a los órganos administrativos de un Estado no emanan de aquella, sino de la ley o del decreto interno que se dicta para darle cumplimiento a la norma de derecho internacional. Como señala Triepel, el derecho internacional equivale a un Mariscal de Campo que da órdenes a los generales pero no a los soldados. Por lo tanto, las obligaciones que surjan del derecho internacional lo serán únicamente para los órganos legislativos (dictar las leyes) o ejecutivo (dictar los decretos) que permitan su cumplimiento, sin que estas sean directamente exigibles a los particulares o a los órganos administrativos o judiciales de un Estado (Vargas Carreño, 1992, p.234). 
Debemos resaltar que la doctrina dualista no tiene incidencia sobre el eventual surgimiento de la responsabilidad internacional para el Estado que incumple una obligación internacional debidamente asumida. Dicha responsabilidad internacional surgirá ante el incumplimiento de la misma aunque no haya sido incorporada al derecho interno del país de que se trate y por ende no haya podido ser conocida y aplicada. En realidad, el efecto concreto que se desprende del dualismo tiene más que ver con la determinación del universo de normas (internas y/o incorporadas) que un juez interno podrá aplicar y un particular deberá observar. En tanto que los órganos del Estado estarán siempre obligados a aplicar su derecho nacional (que puede incluir normas internacionales incorporadas), a nivel internacional el Estado quedará obligado en los términos y alcances impuestos por la norma internacional.

Por su parte, la doctrina monista postula que el derecho internacional y los derechos nacionales forman parte de un solo ordenamiento jurídico, por lo tanto sus normas interactúan pudiendo a veces entrar en conflicto. Para la mayoría de autores, dicho conflicto se resuelve a favor del derecho internacional. Lo importante es que al formar parte de un solo ordenamiento jurídico, las normas internacionales (obviamente solo aquellas que han sido expresamente aceptadas por el Estado en cuestión), conservando su propia naturaleza, se incorporan a los derechos nacionales automáticamente, sin procedimiento ni trámite alguno. Por lo tanto, llegan a obligar directamente a los órganos del Estado (incluyendo a los jueces y a los particulares).

Dentro de la doctrina monista también hay ciertas variantes, desde el monismo radical que defiende la nulidad de las normas internas opuestas al derecho internacional hasta el monismo moderado y el monismo nacionalista. Creemos que el monismo radical reflejado en el párrafo 124 de la sentencia de la Corte IADH en el caso Almonacid Arellano vs. Chile que establece que las leyes contrarias a la Convención carecen desde un inicio de efectos jurídicos, encierra un postulado de realización jurídica imposible puesto que el derecho internacional no tiene capacidad para derogar o anular directamente una norma o acto estatal. En efecto, un acto jurídico interno no puede ser modificado, revisado o abrogado sino siguiendo el mismo procedimiento seguido para su adopción. En ese sentido, el monismo moderado es técnicamente más coherente, en la medida que sostiene que la norma interna opuesta al derecho internacional no es nula ni inexistente, pero engendra la responsabilidad internacional del Estado que la dictó, dejando al derecho interno el margen necesario para adoptar las medidas requeridas dentro de su esfera de actuación (Ruda, 1994).

En el continente americano existen países que se adhieren tanto a la teoría dualista como a la teoría monista antes examinadas. En el caso del dualismo, podemos citar a Colombia y a Chile. En este país, en el caso de los tratados internacionales multilaterales, una vez depositado el instrumento de ratificación, obtenido el certificado 
de depósito respectivo, y teniendo constancia de la entrada en vigor del tratado en cuestión, se elabora un decreto de promulgación el cual es enviado a la Contraloría General de la República, y posteriormente publicado en el Diario Oficial. Algunos países del Caribe como Jamaica se adhieren también al sistema dualista al incorporar las normas internacionales a su ordenamiento jurídico interno únicamente a través de actos específicos.

A diferencia de estos casos, el sistema jurídico argentino no exige que las normas surgidas del derecho internacional se transformen en normativa interna para integrar dicho ordenamiento jurídico. Basta con cumplir dos requisitos: que el tratado se encuentre en vigor y que Argentina haya manifestado su consentimiento en obligarse por dicho tratado (artículo 31 de la Constitución de la Nación Argentina), independientemente de que exista una ley interna que lo apruebe posteriormente, adoptando así una visión monista. Otros países que siguen en principio el sistema monista, aunque algunos de ellos con ciertas variantes son, por citar algunos, Ecuador, Honduras, Paraguay y Perú ${ }^{8}$.

Como habíamos visto, para aquellos países cuyos sistemas están basados en el sistema dualista, la teoría del control convencional difuso plantea enormes problemas de aplicación y no solo teóricos, pues entre el momento en que un Estado manifiesta su voluntad a nivel internacional y el momento en que la norma internacional se incorpora, puede existir un período de tiempo prolongado en el cual el operador interno e incluso los particulares no tendrían por qué conocer la existencia de la obligación internacional, al no ser esta aún parte del cuerpo jurídico con el cual deban manejarse, o al cual tendrían que someterse.

No menos importante es el hecho de que no en pocos casos los países expresan su voluntad para obligarse por un tratado antes de hacer las adecuaciones respectivas en sus legislaciones internas, postergando esta tarea para cuando el tratado ya está en vigor, ocasionando a veces que exista un período, corto en algunos casos y extenso en otros, en que la norma internacional puede entrar en conflicto con la norma interna.

No debemos olvidar tampoco que para los países que adoptan el sistema dualista, lo que el juez interno aplicará al final de cuentas y en todos los casos, es una norma interna, ya sea porque el origen de dicha norma es interno, ya sea porque la norma internacional ya ha sido incorporada y por lo tanto ha pasado a formar parte del derecho doméstico del país en cuestión. En este caso, el juez aplicará la norma que considera de mayor jerarquía, de acuerdo a sus propios referentes internos, sin tener en consideración la naturaleza interna o internacional de dichas normas. Como bien

\footnotetext{
8 En el Perú, el artículo 55 de su Constitución establece que los tratados celebrados por el Estado y en vigor forman parte del derecho nacional.
} 
afirma García Ramírez (2011, p. 128), «el control de convencionalidad entraña la aplicación del orden supranacional, nacionalmente aceptado» (cursiva nuestra).

Asimismo, como ya habíamos señalado, deberíamos descartar el postulado del monismo radical, dado que bajo ningún supuesto la existencia de una norma internacional podría suponer la nulidad automática de una norma interna. Al respecto, debemos señalar que la propia Corte IADH estableció en 1994 mediante su Opinión Consultiva OC-14/94, ante una pregunta planteada por la Comisión Interamericana de Derechos Humanos sobre los efectos de una ley que manifiestamente viole las obligaciones contraídas por el Estado al ratificar la $\mathrm{CADH}$, que:

[...] no le corresponde a la Corte pronunciarse sobre los mismos en el orden interno del Estado interesado. Esa determinación compete de manera exclusiva a los tribunales nacionales y debe ser resuelta conforme a su propio derecho Corte IDH [...] (Artículo 51 Convención Americana sobre Derechos Humanos) (Corte IADH, 1997, párrafo 34).

Es decir, la Corte IADH consideró mediante dicha opinión consultiva que, aun en los casos en que la norma internacional pase a formar automáticamente parte del derecho interno de un Estado, la confrontación entre dicha norma y el ordenamiento jurídico interno de ese país es de competencia y responsabilidad exclusiva del tribunal nacional. Solo una vez resuelta dicha determinación conforme al derecho interno del Estado de que se trate, el tribunal internacional asumirá competencia, para solo entonces y no antes, determinar la responsabilidad internacional del Estado. Esto haría pues muy difícil pretender seguir sosteniendo la teoría del control convencional difuso tal como ha sido planteada por la Corte IADH.

Finalmente, también debemos señalar que para aquellos países que se adhieren al sistema monista moderado tampoco podríamos postular una aplicación inmediata de la norma internacional con preferencia a la norma interna, porque en última instancia ello dependerá de la jerarquía que a dicha norma internacional incorporada le atribuya el derecho interno del Estado en cuestión. Sobre este asunto, también existen grandes diferencias en los países de la región, como veremos en el siguiente capítulo.

\section{La jerarquía de la norma internacional incorporada en el derecho interno de los Estados}

Una vez manifestada válidamente la voluntad a nivel internacional por parte del Estado, asumida la obligación, e incorporada la norma a su sistema jurídico interno, ya sea de manera automática o a través de algún mecanismo de incorporación previsto en la ley, debemos poder determinar qué posición ocupa dicha norma en la estructura jerárquica legal interna de ese Estado. 
En efecto, si la norma internacional incorporada por decir, la propia $\mathrm{CADH}$, se encontrara por encima de todas las normas nacionales incluida la Constitución, se estaría en una situación cercana al auténtico control de convencionalidad (Castilla Juárez, 2016). De estar al mismo nivel que la Constitución, habría que distinguir si son parte de un mismo bloque de constitucionalidad o se manejan como normas independientes. En el primer caso, estaríamos frente a un sistema de control de constitucionalidad que haría innecesario hablar del control de convencionalidad al estar la norma internacional subsumida en aquel ${ }^{9}$. Pero también puede que estén en un rango por debajo de la Constitución y por encima del resto de las leyes, o incluso, al mismo nivel que la ley, con lo que podríamos estar frente al típico control de legalidad (Castilla Juárez, 2016). Más allá de las nomenclaturas, el desafío consiste en poder determinar qué sucede o qué debería hacer el operador en caso de encontrarse con normas contradictorias y de rango distinto.

Si bien cada vez más son los países que otorgan jerarquía constitucional a los tratados internacionales en materia de derechos humanos, superando la clásica concepción de su equiparación legal (Argentina, Chile, Colombia, Costa Rica, Perú y Paraguay), e incluso algunos países otorgan jerarquía supraconstitucional a dichos instrumentos internacionales (Bolivia, Ecuador y Venezuela) (Ferrer Mac-Gregor, 2013), los países en la región aún no siguen un sistema homogéneo.

Por ejemplo, Bolivia, Ecuador y Honduras son países en los cuales el operador interno deberá tener siempre en consideración que el tratado internacional en materia de derechos humanos, una vez aprobado e incorporado, prima sobre cualquier otra norma interna incluyendo la constitucional.

Sin embargo, otros países le otorgan igual rango jerárquico a su Constitución y a los tratados internacionales en materia de derechos humanos. Algunos de ellos tienen un sistema simple, como en el caso de Colombia. En otros casos como en Argentina, algunos tratados de derechos humanos tienen rango constitucional y otros no (estos últimos poseen un estatus supralegal pero infraconstitucional). También tenemos ejemplos como Perú donde el rango de la norma internacional sobre derechos humanos es constitucional pero donde no existe una solución expresa a las situaciones en que ambas normas entren eventualmente en conflicto.

\footnotetext{
9 La consecuencia de la incorporación de los estándares internacionales en materia de derechos humanos a las Constituciones nacionales, ya sea por enmienda de la Constitución, ya sea por el otorgamiento de la condición de rango constitucional o supra constitucional al tratado en el cual están contenidos, es la generación de un llamado «bloque de constitucionalidad» que va a servir de parámetro al control de constitucionalidad de las leyes. Los sistemas internos han de decidir que órgano será el encargado de ejercer ese control (generalmente lo hace un Tribunal o Corte Constitucional).
} 
En todos estos casos en los que la norma internacional en materia de derechos humanos tiene igual jerarquía a la norma constitucional, nada parece indicar por qué en caso de conflicto ente una y otra, el operador interno deba preferir necesariamente la norma internacional. En este caso, el juez tendrá que aplicar los diversos criterios de aplicación e interpretación que utiliza en su actividad regular (como por ejemplo, el principio de que la ley posterior prima sobre la anterior, el principio de que la ley particular prima sobre la general, entre otros), y ello no garantiza necesariamente el resultado que se persigue con la teoría del control convencional difuso. Es más, dicho postulado impondría al juez la obligación de tener que decidirse por la norma internacional en perjuicio de la norma interna, en algunos casos en abierta contradicción con los métodos que normalmente debe utilizar para resolver este tipo de conflictos. En este ámbito, incluso el principio pro personae, tan citado en muchas instancias, encuentra dificultades para su aplicación según la interpretación que algunas Cortes de la región han utilizado como veremos más adelante en el caso de México.

Mayores desafíos encontrará la teoría del control convencional difuso en aquellos países que consideran que la Constitución es la norma suprema del Estado aún por encima de los tratados internacionales, o en aquellos en que la norma internacional tiene el mismo valor jerárquico que las leyes, en cuyo caso debemos aplicar el mismo razonamiento que en el párrafo anterior, solo que esta vez contraponiendo no ya las normas internacionales a la Constitución, sino la norma internacional con aquellas normas de rango legal. Así por ejemplo, en Dominica, la Constitución de dicho país es considerada como la norma suprema y por lo tanto, en caso de que exista un conflicto entre una convención y un domestic statute (término que se refiere a la ley interna en contraposición a las leyes del commonwealth), esta última es la que prevalece (CJI, 2015a).

En otros países la normativa ha sido aclarada mediante desarrollo jurisprudencial. En ese sentido podemos citar a México y a República Dominicana. En el primer caso, el artículo 1 de la Constitución de México dispone que las normas relativas a los derechos humanos se interpretaran de conformidad con los tratados internacionales de los que el Estado mexicano sea parte, favoreciendo en todo momento la protección más amplia. Dentro de este marco, la Suprema Corte de Justicia de la Nación, mediante jurisprudencia del Pleno, determinó que de la interpretación del contenido de las reformas constitucionales de 2011 se desprende que las normas de derechos humanos, independientemente de su fuente, no se relacionan en términos jerárquicos. Entendió que cuando en la Constitución exista una restricción expresa al ejercicio de los derechos humanos, se deberá estar a lo que indica la norma constitucional, ya que el principio que le brinda supremacía comporta el encumbramiento de la Constitución como norma fundamental del orden jurídico mexicano, lo que a su 
vez implica que el resto de las normas jurídicas deben ser acordes con la misma, tanto en un sentido formal como material. Así pues, el cumplimiento del principio de interpretación más favorable a la persona no implica que los órganos jurisdiccionales nacionales dejen de observar los principios constitucionales y legales o las restricciones que prevé la norma fundamental, pues de hacerlo, se provocaría un estado de incertidumbre que afectaría a los destinatarios de la función jurisdiccional ${ }^{10}$.

Otros países como Jamaica no tienen ninguna norma constitucional que resuelva los conflictos entre un tratado y una norma del orden jurídico interno.

En buena cuenta pues, la diversidad de sistemas que adoptan los países de la región con relación a la posición que ocupan las normas internacionales ya incorporadas dentro de la estructura jurídica interna es un obstáculo bastante importante en el intento de aplicar el postulado del control convencional difuso por parte de la Corte $\mathrm{IADH}$, sobre todo en aquellos países en los que el ordenamiento interno prevé que el tratado internacional de derechos humanos tiene un rango igual o inferior a la Constitución. Esta determinación, por lo demás, es siempre interna al ser parte de la atribución soberana del Estado. En el primer caso, es decir, cuando la norma internacional tiene rango constitucional, el juez tendrá que decidirse, en caso de conflicto, por aplicar la norma que resulte adecuada según determinados principios de interpretación y aplicación, que no siempre garantizarán la aplicación de la norma internacional. En el segundo caso, es decir, cuando la norma internacional tiene rango legal por debajo de la Constitución, dicho análisis tendrá que efectuarse a ese nivel, pero la norma Constitucional habrá de primar en todos los casos sobre la norma internacional, desestimándose la aplicación del principio pro personae.

\section{7. ¿Hacia dónde se dirige el principio del control convencional? Conclusiones}

¿Qué debemos entonces esperar de la propuesta de la Corte IADH sobre el control convencional, en especial, la del control convencional difuso que, como hemos visto anteriormente, parece no ir en consonancia con ciertas definiciones e instituciones básicas del derecho internacional general? ¿Qué consecuencias puede tener la actuación de este tribunal cuando se basa en una figura que exige a los operadores internos aplicar directamente no solo el tratado internacional sino también el precedente jurisprudencial? ¿Qué sucedería si los operadores internos, al aplicar el postulado del

\footnotetext{
${ }^{10}$ En México, el Poder Judicial de la Federación ha determinado que incluso los criterios y directrices desarrollados por órganos internacionales encargados de la promoción y protección de los derechos fundamentales son útiles para que los Estados guíen sus prácticas, sin que ello implique desconocer la observancia primigenia del orden jurídico nacional, pues la consulta de estas directrices solo reporta efectos prácticos derivados de la experiencia acogida por dichos órganos (CJI, 2015b).
} 
control convencional difuso, se convierten a su vez en «intérpretes de las interpretaciones» hechas por la Corte IADH?

En noviembre de 2017, en una sentencia del Tribunal Constitucional Plurinacional de Bolivia, los jueces se pronunciaron por la inaplicabilidad de normas constitucionales que limitaban la reelección del presidente y de los miembros del Congreso por entender que contradecían normas de la CADH y ciertos fallos de la Corte IADH considerados vinculantes para Bolivia, no obstante la manifestación popular expresada en forma directa mediante un referendo constitucional. En dicho referendo, la mayoría de la población había rechazado una eventual modificación del texto constitucional en el sentido de permitir dicha reelección. Este caso hizo evidente los riesgos de aplicar el postulado del control convencional difuso y dejarlo en manos de operadores internos que eventualmente podrían interpretar de forma equivocada o «conveniente» los precedentes jurisprudenciales de la Corte IADH e ir en contra de lo dispuesto en su propia Constitución y de los resultados de un referendo o, por otro lado, hacerlo en consonancia con algunos pocos antecedentes y no sobre la base del universo de precedentes existentes.

Este ejemplo grafica cómo, de aceptarse la aplicación del control convencional difuso, la Corte IADH debería ser capaz de supervisar la conformidad de todas las interpretaciones realizadas por el amplio universo de operadores internos de la región con su propia jurisprudencia, a riesgo de generar una dispersión e incoherencia que contagiaría tarde o temprano el SIDH. A esta imposibilidad fáctica se suma el hecho de que no todos los casos llegarán a la atención de la Corte IADH para asegurar dicha armonización, ya sea porque el Estado en cuestión no es parte de la $\mathrm{CADH}$, o no ha aceptado la jurisdicción de la Corte, o porque el caso no fue elevado al plano internacional, o de haberlo sido, quedó exclusivamente bajo consideración de la Comisión Interamericana de Derechos Humanos. Los riesgos pues, son grandes.

Es indiscutible que el control convencional ha constituido una herramienta de la mayor importancia en el SIDH. Sin embargo, se trata de una institución propia del derecho internacional general y por lo tanto es en dicho ámbito que se deben definir las bases sobre las cuales opera y los alcances de su aplicación, con el objetivo de garantizar la debida consistencia de la labor de los diversos tribunales internacionales que lo utilizan y de las consecuencias de sus decisiones con relación a los sujetos de derecho internacional.

No obstante ello, como hemos visto a lo largo de este trabajo, la Corte IADH ha ampliado el alcance de dicho concepto a través de su jurisprudencia, utilizando como analogía la figura del control difuso de constitucionalidad. Sin embargo, dicha analogía es inapropiada porque este tipo de control presupone la actuación de los 
diversos actores y operadores que lo utilizan dentro de un marco jurídico único, sujetos a las mismas normas sustantivas y procedimentales, lo que no sucede con el SIDH vis-a-vis los ordenamientos jurídicos internos de los países en la región. Entre las varias características que presenta la figura del control convencional difuso, se atribuyen a una amplia variedad de operadores ciertas competencias que no están expresamente reconocidas en su derecho interno, lo que crea inconsistencias entre la pretensión de dicha aplicación y las regulaciones procesales en vigor, pudiendo generar como consecuencia una falta efectiva de protección o un vacío perjudicial para asegurar las debidas garantías.

Asimismo, el concepto tradicional de control convencional pone el énfasis en la adecuación de la conducta del Estado con la obligación internacional contraída, mientras que el postulado del control convencional difuso pone el énfasis en la comparación entre la norma nacional y la obligación internacional. Se desconoce así la naturaleza jurídica de la responsabilidad internacional y del procedimiento que permite determinarla el cual exige como requisitos esenciales, entre otros, el agotamiento de los recursos internos, y toma en consideración la posible existencia de una serie de situaciones que pueden llegar a excluir la ilicitud del hecho. La mera comparación entre normas (la interna y la internacional) pertenece a una etapa muy inicial y previa a todas estas consideraciones, ya que elimina la posibilidad de que el Estado pueda subsanar mediante una determinada conducta y dentro de su esfera interna, los efectos de la aplicación de una norma doméstica que vulnere los derechos humanos, todo lo cual va en consonancia además con la naturaleza misma del SIDH. También debemos tener en cuenta que la figura del control convencional difuso no tiene base en la $\mathrm{CADH}$ o en ningún otro instrumento de derecho internacional general o de derechos humanos, a diferencia del control convencional tradicional que se encuentra implícito en las atribuciones de los tribunales internacionales desde que son establecidos por un tratado específico.

Debemos recordar además que las decisiones de la Corte IADH son obligatorias para las partes en litigio y respecto del caso que ha sido decidido. Así, los fallos e interpretaciones de la Corte $\mathrm{IADH}$, al no ser esta un tribunal supranacional dentro del SIDH y por ende tampoco constituir una cuarta instancia, no pueden considerarse vinculantes ni para los Estados ajenos a un caso particular, ni para los tribunales internos de los países de la región, salvo por decisión propia del Estado. Admitir lo contrario implicaría que la Corte IADH debería fallar tomando también en consideración el derecho interno del Estado correspondiente, algo que no es propio de su naturaleza. También sería desconocer el hecho de que la Corte IADH no es una corte de alzada, sino que los casos que llegan a su atención deben pasar por el filtro de la Comisión Interamericana de Derechos Humanos como instancia intermedia. 
La teoría general de las fuentes del derecho internacional respalda también estas afirmaciones, pues considera que las decisiones de los tribunales internacionales no son fuente autónoma o creadora de derecho sino que solo cumplen una función probatoria de la existencia de las normas jurídicas e interpretativas del contenido de las mismas. Aún en los casos en que algunos países han admitido que la jurisprudencia de la Corte IADH tiene el carácter de precedente, la fuente de dicha obligatoriedad proviene ya sea de un tratado internacional para el derecho internacional o de las decisiones de los tribunales internos para el derecho interno, no de la naturaleza jurídica misma de la decisión internacional.

Al mismo tiempo, el ejercicio de interpretación tiene como objetivo determinar el sentido y el alcance de la norma, no así la creación de nuevas normas jurídicas. Esto último extralimitaría la naturaleza misma de la función jurisprudencial. Esta determinación no se hace en abstracto sino con relación a la aplicación de la norma a un caso concreto. Por lo tanto, el resultado de dicho proceso no podrá ser extensivo a otros casos que no repliquen exactamente las mismas circunstancias, impidiendo de suyo la posibilidad de generar de nuevas normas internacionales, las cuales tienen vocación general.

Adicionalmente, el control convencional difuso basado en antecedentes jurisprudenciales no es de fácil aplicación a la mayoría de los Estados parte en la CADH que provienen de un sistema de derecho civil en el que la fuente principal de derecho es la ley y no el precedente.

Mención aparte merecen los problemas que presenta la figura del control convencional difuso cuando estamos hablamos de la diversidad de sistemas que existen en nuestra región tanto para la incorporación de la norma internacional, como para la determinación del lugar que ocupará dicha norma, una vez incorporada, dentro de la jerarquía normativa interna de cada país. Según las diferentes modalidades a las que se adscriban los distintos países, las dificultades para la aplicación de un control convencional difuso se irán incrementando.

El control de convencionalidad difuso, tal como ha sido postulado por la Corte $\mathrm{IADH}$, no se adecúa pues a los parámetros establecidos por el derecho internacional general, de allí que las posibilidades reales de su efectivo desarrollo e implementación sean escasas salvo que vengan complementadas por otros esfuerzos o salvo que se pretenda negar que el derecho internacional de los derechos humanos no forma parte del derecho internacional, con lo que tendría que empezar delineando desde cero sus bases y sus fundamentos. Un factor coadyuvante podría ser que las propias cortes internas de los países de la región empiecen a generar una costumbre internacional respecto de dicha aplicación, que además de la práctica generalizada aporte también 
el elemento psicológico de la costumbre, es decir, la convicción de que existe una necesidad jurídica para actuar de esta manera. Algunas cortes internas ya han iniciado este ejercicio, pero ello implica haber superado un umbral de actuación para el cual no todos los Estados de la región están aún preparados. La gran mayoría sigue considerando la separación de poderes y el respeto de las funciones propias de cada uno de ellos, una característica necesaria de sus sistemas democráticos. Si bien los tribunales internos deben ser capaces de generar con su actuación ciertos cambios e impactos, dicha separación de poderes sigue siendo considerada como la garantía del Estado de derecho en la región.

El control convencional difuso no puede por ahora ser más que un elemento coadyuvante o persuasivo en la labor de los jueces internos de los Estados, y es sobre ese sentido que tenemos que seguir operando y mejorando los contenidos. Este es un hecho que hay que reconocer en vez de ignorar. La amplia difusión de los estándares jurídicos de protección de los derechos humanos en el sistema interamericano (tanto las normas duras como el soft law, incluyendo no solo la jurisprudencia sino los pronunciamientos de la Organización regional por excelencia como es la OEA a través de sus resoluciones anuales) junto con esfuerzos para lograr una estrecha cooperación entre todos los actores del sistema son pasos necesarios hacia cualquier intento de éxito en la aplicación de esta propuesta. La gran batalla por los derechos humanos se ganará en el ámbito interno del cual es coadyuvante y subsidiario el marco internacional.

Debemos recordar que en la cúspide del SIDH está el individuo y el objetivo central de este sistema es lograr la más amplia y efectiva protección de sus derechos. Todos los demás actores, internos e internacionales, deben alinear su actividad con este fin esencial, recordando además que el juez no es el único actor que tiene un rol por cumplir en los intentos por garantizar un pleno acceso a la justicia. Si para ello se tienen que adecuar los patrones, criterios y conductas que han permeado el sistema en las últimas décadas, debemos hacerlo, teniendo como referencia un parámetro mínimo y esencial que es el respeto por el derecho, por su contenido y por la forma como se ha establecido y diseñado. Esto será lo único que permita que todos los actores del sistema sepan y sientan que están interactuando de manera segura dentro del marco de legalidad debido.

Dentro de este esfuerzo, y como bien afirma el juez Vio Grossi (2015b), la Corte IADH debe hacer honor a la alta función que se le ha asignado y por lo tanto desenvolverse en el ámbito propio de una entidad jurisdiccional internacional. En ello radica su fortaleza y de ello depende el desarrollo sostenible y exitoso del SIDH. 


\section{Referencias bibliográficas}

Becerra Ramírez, M. (1998). Las decisiones judiciales como fuente del derecho internacional de los derechos humanos. En Liber Amicorum. Héctor Fix-Zamudio (vol. I, pp. 431-446). San José de Costa Rica: Secretaría de la Corte Interamericana de Derechos Humanos.

Castilla Juárez, K.A. (2016). Control de convencionalidad interamericano: una propuesta de orden ante diez ańos de incertidumbre. Revista del Instituto Interamericano de Derechos Humanos, 64, 87-125.

Comité Jurídico Interamericano. (2015a). Respuesta brindada por Dominica mediante Nota PM.DOM.DC.31.16 de 23 de agosto de 2016, al cuestionario elaborado por el Comité Jurídico Interamericano de la OEA, CJI/doc.492/15 rev.1.

Comité Jurídico Interamericano. (2015b). Respuesta brindada por México al cuestionario elaborado por el Comité Jurídico Interamericano de la OEA, CJI/doc.492/15 rev.1.

Corte IADH. (2003). Caso Myrna Mack Chang vs. Guatemala. Fondo, Reparaciones y Costas. Sentencia del 25 de noviembre de 2003. Serie C No. 101.

Corte IADH. (2004). Caso Tibi vs. Ecuador. Excepciones Preliminares, Fondo, Reparaciones y Costas. Sentencia del 7 de septiembre de 2004. Serie C No. 114.

Corte IADH. (2006). Caso Vargas Areco vs. Paraguay. Sentencia del 26 de septiembre de 2006. Serie C No. 155.

Corte IADH. (2006). Caso Almonacid Arellano y otros vs. Chile. Excepciones Preliminares, Fondo, Reparaciones y Costas. Sentencia de 26 de septiembre de 2006. Serie C No. 155.

Corte IADH. (2006). Caso Trabajadores Cesados del Congreso (Aguado Alfaro y otros) vs. Perú. Excepciones Preliminares, Fondo, Reparaciones y Costas. Sentencia de 24 de noviembre de 2006. Serie C No. 158.

Corte IADH. (2010). Caso Cabrera García y Montiel Flores vs. México. Excepción Preliminar, Fondo, Reparaciones y Costas. Sentencia de 26 de noviembre de 2010. Serie C No. 220.

Corte IADH. (2011). Caso Gelman vs. Uruguay. Fondo y Reparaciones. Sentencia de 24 de febrero de 2011. Serie C No. 221.

Corte IADH. (1997). Informes de la Comisión Interamericana de Derechos Humanos (Art. 51 Convención Americana sobre Derechos Humanos). Opinión Consultiva OC-15/97 de 14 de noviembre de 1997. Serie A No. 15.

Ferrer Mac-Gregor, E. (2013). El control difuso de convencionalidad en el estado constitucional. Recuperado de http://biblio.juridicas.unam.mx

García Ramírez, S. (2011). El control judicial interno de convencionalidad. IUS Revista del Instituto Ciencias Jurídicas de Puebla, 5(28), 123-159.

Gozaíni, O. A. (1998). Los efectos de las sentencias de la Corte Interamericana de Derechos Humanos en el derecho interno. En Libro de homenaje a Héctor Fix-Zamudio (pp. 819 y ss.). San José de Costa Rica: Corte Interamericana de Derechos Humanos. 
Jiménez Piernas, C. (2011). Introducción al Derecho Internacional Público. Práctica de España $y$ de la Unión Europea. Madrid: Tecnos.

Pastor Ridruejo, J. A. (1986). Curso de Derecho Internacional Público. Madrid: Tecnos.

Rodas Balderrama, V. H. (2016). Aplicación del control de convencionalidad del corpus iuris interamericano de los derechos humanos. Revista del Instituto Interamericano de Derechos Humanos, 64, 311-345.

Ruda, J. M. (1994). Relación jerárquica entre los ordenamientos jurídicos internacional e interno. Reexamen de los Problemas Teóricos. En El derecho internacional en un mundo en transformación - Homenaje al profesor Eduardo Jiménez de Aréchaga (t. I.). Montevideo: Fundación de Cultura Universitaria.

Sagües, N. (2010). Dificultades operativas del control de convencionalidad en el sistema interamericano. La Ley, t. 2010-D.

Vargas Carreño, E. (1992). Introducción al Derecho Internacional. San José: Juricentro.

Vicente Gudiel, J. A. y Véliz Arriaga, L. A. (2016). Reflexiones sobre el ejercicio del control de convencionalidad en Guatemala. Revista del Instituto Interamericano de Derechos Humanos, 64, 59-86.

Vio Grossi, E. (2015a). Intervención en la presentación del libro Convención Americana sobre Derechos Humanos: comentarios. Valparaíso: Fundación Konrad Adenauer y Facultad de Derecho de la Pontificia Universidad Católica de Valparaíso. Recuperado de https://www.kas.de/c/document_library/ get_file?uuid=696a2e04-554a-4a0e-1ec3-6fb91456b888\&groupId=271408

Vio Grossi, E. (2015b). Jurisprudencia de la Corte Interamericana de Derechos Humanos: ¿del control de convencionalidad a la supranacionalidad? Anuario de Derecho Constitucional Latinoamericano, 21, 93-112. Recuperado de https:/www.kas.de/es/web/rspla/ einzeltitel/-/content/anuario-de-derecho-constitucional-latinoamericano-20151

Recibido: 30 de marzo de 2020

Aprobado: 27 de agosto de 2020 